\title{
In vitro effectiveness of different endodontic irrigants on the reduction of Enterococcus faecalis in root canals
}

\author{
Singamaneni Vijaykumar ${ }^{1}$, Madiraju GunaShekhar ${ }^{2}$, Sura Himagiri $^{3}$ \\ ${ }^{1}$ Associate Professor, Conservative Dentistry and Endodontics. NIMS Dental College, Jaipur, India. \\ ${ }^{2}$ Associate Professor, Faculty of Pediatric Dentistry. NTRUHS, AP, India. \\ ${ }^{3}$ Associate Professor and Consultant Endodontist. Hyderabad, AP, India.
}

Correspondence:

House \# 40-6-5(22/1), 3rd lane, 3rd cross,

Thurpukamma palem, Ongole-1, AP, India

Email:drvijjuendo@gmail.com

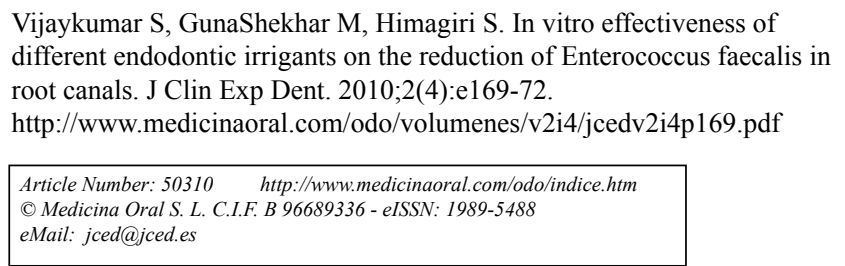

\begin{abstract}
Objective: To compare the reduction of E. faecalis counts in root canals produced by irrigation with distilled water, hydrogen peroxide, sodium hypochlorite, chlorhexidine, and combinations of solutions, in vitro.

Study Design: Study sample included sixty mandibular premolar teeth mounted in dental stone. Root canals were prepared using crown down technique under distilled water irrigation. Specimens were sterilized overnight by ethylene oxide gas. Each canal was completely filled up with the E. faecalis suspension and incubated at $37^{\circ} \mathrm{C}$ for 24 hours. Root canals were irrigated with the test solutions. A volume of $5 \mathrm{ml}$ of the tested irrigant was used for each sample with an exposure period of 5 minutes. $10 \mathrm{ml}$ of distilled water was used as final irrigant in all the samples. Canals were sampled before and after irrigation. After serial dilutions, samples were plated onto Mitis salivarius agar, and the colony forming units were counted. Results were analyzed by Chi-square test, Fisher's exact test, and one-way ANOVA followed by multiple range Tukey HSD test with the level of significance set at $\mathrm{P}<0.05$.

Results and Conclusions: Reduction of colony counts in distilled water group was significantly lower than the mean reduction in all the other groups. However, no other contrasts are statistically significant. Combination of sodium hypochlorite and chlorhexidine showed the most effective antimicrobial activity followed by sodium hypochlorite and hydrogen peroxide together. Hydrogen peroxide was the least effective irrigant when used alone.
\end{abstract}

Key words: Chlorhexidine, E. faecalis, hydrogen peroxide, root canal, sodium hypochlorite. 


\section{Introduction}

Access cavity preparation, biomechanical preparation and obturation of the root canal constitute the endodontic triad. Of these three steps, biomechanical preparation plays a major role in determining the success of the treatment. Although the root canal flora is dominated by obligate anaerobic bacteria, some facultative strains like Enterococcus faecalis, Staphylococcus aureus have been involved in persistent infections, influencing the prognosis of the root canal treatment (1).

The majority of bacteria found in the root canal micro flora may be removed simply by the mechanical action of endodontic instruments. However, due to the mechanical complexities of many root canals, even after mechanical procedures, organic residues and bacteria located deep in the dentinal tubules cannot be reached. Therefore various irrigating solutions have been used during and immediately after root canal preparation to remove debris and necrotic pulp tissue and to eliminate microorganisms that cannot be reached by mechanical instrumentation (2). The purpose of this in vitro study was to compare the effectiveness of different irrigating agents in reducing E. faecalis from the root canals.

\section{Materials and methods}

Tooth preparation

Sixty freshly extracted mandibular premolar teeth were selected for the study. Conventional access cavity preparations were done and working length was determined by placing a \#10 file into the root canal until it was visible at the apical foramen and then $1 \mathrm{~mm}$ was deducted from that length. After working length determination the apical foramen was sealed with epoxy resin to prevent bacterial leakage. Teeth were mounted vertically in dental stone blocks to make both handling and identification easier. Biomechanical preparation was done using crown-down technique under irrigation with distilled water. Canals were instrumented to a master apical file size of \#50. Then the specimens were sterilized overnight by ethylene oxide gas.

Specimen contamination

Pure culture of E.faecalis grown in Brain Heart Infusion broth (BHI) was used to contaminate the root canals. A suspension of E.faecalis cells was prepared in BHI, which had its optical density adjusted to approximately $1 \times 108 \mathrm{cfu} / \mathrm{ml}$ by comparing its turbidity to a Mc Farland $0.5 \mathrm{BaSO} 4$ standard. Sterilized stone blocks containing the teeth were opened in a laminar airflow cabinet. Each root canal was completely filled up with the E. faecalis suspension using sterile $1 \mathrm{ml}$ tuberculin syringes. The blocks were then placed inside sterile plastic bags and incubated at $370 \mathrm{C}$ for 24 hours.

The teeth were divided into six groups according to the solutions used for irrigation. Group A: Root canals were irrigated with distilled water and kept as control group; Group B: 3\% Hydrogen peroxide (HP); Group C: 3\% Sodium hypochlorite $(\mathrm{NaOCl})$; Group D: 0.2\% Chlorhexidine gluconate $(\mathrm{CHX})$; Group E: Alternating solutions of $3 \% \mathrm{HP}$ and $3 \% \mathrm{NaOCl}$; Group F: Alternating solutions of $3 \% \mathrm{NaOCl}$ and $0.2 \% \mathrm{CHX}$. A volume of $5 \mathrm{ml}$ of the tested irrigant was used for each sample. Irrigants were allowed to remain in the canal for 5 minutes. Then a final irrigation was performed using $10 \mathrm{ml}$ of distilled water in each sample.

Sampling technique

Root canals were sampled before and after irrigation. Each sample was taken by using three paper points. After sampling, paper points were transferred to tubes containing $1 \mathrm{ml}$ of peptone water and vortexed for 1 minute. After 10-fold serial dilutions in peptone water, aliquots of $0.01 \mathrm{ml}$ were placed on to Mitis Salivarius Agar plates and incubated at $370 \mathrm{C}$ for 48 hours and then colony forming units were counted.

One-way ANOVA and Multiple range test by TukeyHSD was used for mean comparison between the groups. Student's paired 't' test was used to assess signi-

\begin{tabular}{|c|c|c|c|c|c|c|c|c|c|c|c|c|}
\hline \multirow{3}{*}{ Samples } & \multicolumn{2}{|c|}{$\mathbf{A}$} & \multicolumn{2}{|c|}{ B } & \multicolumn{2}{|c|}{$\mathbf{C}$} & \multicolumn{2}{|c|}{ D } & \multicolumn{2}{|c|}{$\mathbf{E}$} & \multicolumn{2}{|c|}{$\mathbf{F}$} \\
\hline & \multicolumn{2}{|c|}{ Distilled Water } & \multicolumn{2}{|c|}{$\begin{array}{ll}\text { Hydrogen } & \text { Pe- } \\
\text { roxide }(\mathrm{HP})\end{array}$} & \multicolumn{2}{|c|}{$\mathrm{NaOCl}$} & \multicolumn{2}{|c|}{$\mathrm{CHX}$} & \multicolumn{2}{|c|}{$\mathrm{HP}+\mathrm{NaOCl}$} & \multicolumn{2}{|c|}{$\mathrm{NaOCl}+\mathrm{CHX}$} \\
\hline & PRE & POST & PRE & POST & PRE & POST & PRE & POST & PRE & POST & PRE & POST \\
\hline 1 & 700 & 180 & 700 & $\mathrm{NC}$ & 600 & 12 & 580 & $\mathrm{NC}$ & 400 & $\mathrm{NC}$ & 300 & $\mathrm{NC}$ \\
\hline 2 & 870 & 130 & --- & --- & 600 & $\mathrm{NC}$ & 500 & 23 & 300 & $\mathrm{NC}$ & 600 & 03 \\
\hline 3 & 300 & 150 & 300 & 18 & 400 & $\mathrm{NC}$ & 350 & 05 & 600 & 01 & 500 & $\mathrm{NC}$ \\
\hline 4 & 500 & 200 & 400 & 01 & 800 & 04 & 500 & 03 & 650 & $\mathrm{NC}$ & 300 & $\mathrm{NC}$ \\
\hline 5 & 360 & 180 & 800 & $\mathrm{NC}$ & 400 & $\mathrm{NC}$ & 130 & $\mathrm{NC}$ & 500 & $\mathrm{NC}$ & 500 & $\mathrm{NC}$ \\
\hline 6 & 760 & 120 & 460 & $\mathrm{NC}$ & 430 & $\mathrm{NC}$ & 150 & $\mathrm{NC}$ & 400 & $\mathrm{NC}$ & 400 & $\mathrm{NC}$ \\
\hline 7 & 230 & 80 & 450 & 04 & 450 & 03 & 200 & 09 & 500 & 01 & 500 & $\mathrm{NC}$ \\
\hline 8 & 400 & 180 & 700 & 12 & 300 & $\mathrm{NC}$ & 350 & $\mathrm{NC}$ & 400 & $\mathrm{NC}$ & 400 & $\mathrm{NC}$ \\
\hline 9 & 280 & 110 & 800 & 22 & 350 & 09 & 600 & 11 & 450 & 03 & 350 & $\mathrm{NC}$ \\
\hline 10 & 600 & 140 & 600 & 03 & 300 & $\mathrm{NC}$ & 250 & $\mathrm{NC}$ & 450 & $\mathrm{NC}$ & 300 & $\mathrm{NC}$ \\
\hline
\end{tabular}

NC-Negative Culture; NaOCl-Sodium hypochlorite; CHX-Chlorhexidine; PRE-Before irrigation; POST-After irrigation

*One-way ANOVA followed by Multiple Range Test by Tukey-HSD procedure were used to identify the significant groups at $5 \%$ level.

Table 1. Distribution of number of colony forming units of E. faecalis before and after using irrigants among the study groups 


\begin{tabular}{|c|c|c|c|c|c|c|c|}
\hline \multirow{2}{*}{\multicolumn{2}{|c|}{ Groups }} & \multicolumn{2}{|c|}{ Negative Cultures } & \multicolumn{2}{|c|}{$\begin{array}{l}\text { Positive } \\
\text { Cultures }\end{array}$} & \multirow{3}{*}{ P-value * } & \multirow{2}{*}{$\begin{array}{c}\text { Significant\# } \\
\text { groups at } 5 \% \\
\text { level }\end{array}$} \\
\hline & & No. & $\%$ & No. & $\%$ & & \\
\hline A & Distilled water & 0 & $0 \%$ & 10 & $100 \%$ & & \multirow{6}{*}{$\begin{array}{l}\text { A vs C } \\
\text { A vs D } \\
\text { A vs E } \\
\text { A vs F } \\
B \text { vs F }\end{array}$} \\
\hline B & Hydrogen peroxide (HP) & 3 & $33.3 \%$ & 6 & $66.7 \%$ & & \\
\hline $\mathrm{C}$ & Sodium hypochlorite $(\mathrm{NaOCl})$ & 6 & $60 \%$ & 4 & $40 \%$ & & \\
\hline $\mathrm{D}$ & Chlorhexidine (CHX) & 5 & $50 \%$ & 5 & $50 \%$ & & \\
\hline $\mathrm{E}$ & $\mathrm{HP}+\mathrm{NaOCl}$ & 7 & $70 \%$ & 3 & $30 \%$ & & \\
\hline $\mathrm{F}$ & $\mathrm{NaOCl}+\mathrm{CHX}$ & 9 & $90 \%$ & 1 & $10 \%$ & 0.002 ( $\mathrm{sig})$ & \\
\hline
\end{tabular}

* Chi- square test with continuity correction was used to calculate the P-value.

\# Fisher's Exact Test (2- tailed) was used to identify the significant groups at $5 \%$ level.

Table 2. Comparison of proportion of negative cultures in different study groups

ficance between pre-irrigation and post-irrigation values of each group. Chi-square analysis was employed to find the significant differences in the distribution of negative cultures between the groups, whereas significance in the distribution of negative cultures between two groups was tested by Fisher's Exact test.

\section{Results}

Statistical analysis by one-way ANOVA followed by Multiple Range Test by Tukey-HSD (Honestly Significant Difference) procedure showed that there is no significant difference in mean changes between different study groups $(\mathrm{P}>0.05)$. Student's paired $t$ - test showed that there is a significant change from pre-irrigation values to post-irrigation values in each study group $(\mathrm{P} \leq$ 0.001 ) (Table 1). Proportion of negative cultures in group A $(0 \%)$ is significantly lower than those in all the other groups. Also, the proportion of negative cultures in group B (33.3\%) has shown to be significantly lower compared to that in group F (90\%). However, no other contrasts are statistically significant. (Table 2)

\section{Discussion}

E. faecalis, a facultative gram-positive anaerobe, has been implicated in persistent root canal infections $(3,4)$. It is well recognized as a pathogen associated with persistent apical periodontitis in endodontically treated teeth, easy to culture and has been used successfully in several studies on the efficacy of endodontic irrigants $(1,5-7)$. Various studies reported the use of paper points for collecting microbiological samples from the root canals (8-10). Paper point cultures of the root canal detected bacteria more frequently than dentin filling cultures on the reamers. In the present study three paper points were used for collecting the samples from each canal.

Mitis salivarius agar was used because it allows the growth of selective oral microflora such as Streptococci and Enterococci including E. faecalis. Thus the risk of false results due to the growth potential of bacterial contaminants, which might have occurred during handling, was reduced. Distilled water was used as control as it was devoid of antibacterial action when compared to other test solutions which had some amount of known antibacterial activity. Our results showed $66 \%$ bacterial reduction in the distilled water group. This may be due to its basic ability to flush out debris from the root canal. It was also interesting to note that all the cultures obtained following distilled water irrigation remained positive for E. faecalis. The significant bacterial reduction in the distilled water treated group may also be attributed to the volume of the solution used in each sample $(15 \mathrm{ml})$.

Mechanical effects during irrigation are generated by the flow and back flow of irrigant solution in the root canal. Regardless of the type of irrigant used, the bacterial population inside the root canal is significantly reduced by the mechanical effects of irrigation (11). However there was a highly significant difference in colony counts after irrigation between the distilled water group and the experimental groups, there by stressing the need for an antimicrobial irrigant during biomechanical preparation of the root canal.

The mechanism of action of hydrogen peroxide (HP) involves the reaction of superoxide ions to produce hydroxyl radicals which can attack membrane lipids, DNA and other essential cell components (12). Heling \& Chandler (12) in a study on extracted bovine incisors reported that $3 \% \mathrm{HP}$ required 10 minutes to eliminate $\mathrm{E}$. faecalis. In the present study, 3\% HP produced 33.3\% negative cultures of $\mathrm{E}$. faecalis after 5-minute exposure period indicating that 5-minute exposure period is not enough for exhibiting satisfactory antibacterial effect.

No general agreement exists regarding the optimal concentration of $\mathrm{NaOCl}$, which ranges from $0.5 \%$ to $5.25 \%$. Even though antibacterial effects of $\mathrm{NaOCl}$ are well recognized, the exact mechanism of microbial killing is not well elucidated. In the present study, $3 \% \mathrm{NaOCl}$ showed $60 \%$ negative cultures at an exposure time of 5 minutes. Our findings are in corroboration with other studies thus reemphasizing that antimicrobial action of $\mathrm{NaOCl}$ is proportional to its concentration (3).

A significant reduction in colony forming units with $0.2 \%$ CHX found in this study corroborates with the findings of other studies $(13,14)$ which may be suggestive 
of obtaining higher success rates in root canal therapy due to greater reduction in microorganisms (5). The results of the present study are in agreement with other studies $(6,15)$ which showed CHX to be as effective as antimicrobial agent as $\mathrm{NaOCl}$, in vitro. Systematic review and meta-analysis on the efficacy of $\mathrm{NaOCl}$ and CHX on E.faecalis evaluated using polymerase chain reaction and culture techniques showed low ability to eliminate E.faecalis (16).

The combined use of $\mathrm{NaOCl}$ and $\mathrm{CHX}$ within the root canal resulted in a greater reduction of microbial flora when compared to the individual use of $\mathrm{NaOCl}$ or $\mathrm{CHX}$. The reason was attributed to the additive antibacterial effect of the combination (10). In this study though statistically not significant, proportion of negative cultures in individual groups, $\mathrm{NaOCl}(60 \%)$ and CHX (50\%), is comparatively less than their combination $(90 \%)$. However the proportion of negative cultures in HP group $(33.3 \%)$ is significantly less in comparison to $\mathrm{NaOCl}$ and CHX combination group (90\%). The synergistic effects gained by the $\mathrm{NaOCl}$ and $\mathrm{CHX}$ combination include an additive antimicrobial action and better tissue dissolution property.

The present study showed that in groups where individual solutions were used (groups B, C, and D) the reduction rate in the bacterial colony counts was more than $98 \%$ in all the three groups $(p<0.0001)$. However there was no significant difference in the post irrigant bacterial colony counts and the percentage of negative cultures among the three groups. In this study combinations of irrigants were tried with the idea of maximizing the advantages of the ideal properties of individual irrigants and at the same time minimizing their disadvantages.

Apical enlargement during canal cleaning and shaping procedures has the potential to eliminate more bacteria from the root canal system (11). In the present study apical preparations were done up to $50 \mathrm{~K}$-file in all the specimens. After bacterial inoculation, mechanical instrumentation of the canal was not performed, as the purpose of this study was solely to determine the antimicrobial effectiveness of the irrigants following a standardized irrigation protocol.

This study tested the antimicrobial action of $\mathrm{HP}, \mathrm{NaOCl}$, and CHX and combinations, but antimicrobial activity is not the sole requirement of an endodontic irrigant. Root canal irrigants should also have other characteristics, such as high detergent power, low surface tension, ease of handling and high proteolytic and tissue dissolving power. CHX does not possess pulp tissue dissolving ability unlike $\mathrm{NaOCl}(17,18)$ though there are reports of its tissue debriding capability (2). Until it is proven to be able to effectively dissolve pulp tissues, $\mathrm{NaOCl}$ must be still considered the irrigant of choice. CHX may still be used as an adjunct with $\mathrm{NaOCl}$ as an alternate endodontic irrigant due to its high bacterial adhesion reduction capability albeit being not a caustic solution, non irritant and non allergenic. Furthermore, its excellent antimicrobial properties also might indicate it as a useful substitute in patients who are allergic to $\mathrm{NaOCl}$.

\section{References}

1. Siqueira JF Jr, Machado AG, Silveira RM, Lopes HP, de Uzeda M. Evaluation of the effectiveness of sodium hypochlorite used with three irrigation methods in the elimination of Enterococcus faecalis from the root canal, in vitro. Int Endod J. 1997;30:279-82.

2. Ferraz CC, Gomes BP, Zaia AA, Teixeira FB, Souza-Filho FJ. In vitro assessment of the antimicrobial action and the mechanical ability of chlorhexidine gel as an endodontic irrigant. J Endod. 2001;27:452-5.

3. Gomes BP, Ferraz CC, Vianna ME, Berber VB, Teixeira FB, Souza-

Filho FJ. In vitro antimicrobial activity of several concentrations of sodium hypochlorite and chlorhexidine gluconate in the elimination of Enterococcus faecalis. Int Endod J. 2001; 34: 424-8.

4. Buck RA, Eleazer PD, Staat RH, Scheetz JP. Effectiveness of three endodontic irrigants at various tubular depths in human dentin. J Endod. 2001;27:206-8.

5. Parsons GJ, Patterson SS, Miller CH, Katz S, Kafrawy AH, Newton $\mathrm{CW}$. Uptake and release of chlorhexidine by bovine pulp and dentin specimens and their subsequent acquisition of antibacterial properties. Oral Surg Oral Med Oral Pathol. 1980; 49: 455 - 9.

6. Vahdaty A, Pittford TR, Wilson RF. Efficacy of chlorhexidine in disinfecting dentinal tubules in vitro. Endod Dent Traumatol. 1993;9:243-8.

7. Ayhan H, Sultan N, Cirak M, Ruhi MZ, Bodur H. Antimicrobial effects of various endodontic irrigants on selected microorganisms. Int Endod J. 1999;32:99-102.

8. Siqueira JF Jr, Rocas IN, Favieri A, Lima KC. Chemomechanical reduction of the bacterial population in the root canal after instrumentation and irrigation with $1 \%, 2.5 \%$, and $5.25 \%$ sodium hypochlorite. J Endod. 2000;26:331-4.

9. Dalton BC, Orstavik D, Phillips C, Pettiette M, Trope M. Bacterial reduction with nickel-titanium rotary instrumentation. J Endod. 1998;24:763-7.

10. Kuruvilla JR, Kamath MP. Antimicrobial activity of $2.5 \%$ sodium hypochlorite and $0.2 \%$ chlorhexidine gluconate seperately and combined, as endodontic irrigants. J Endod. 1998;24:472-6.

11. Siqueira JF Jr, Lima KC, Magalhaes FA, Lopes HP, de Uzeda M. Mechanical reduction of the bacterial population in the root canal by three instrumentation techniques. J Endod. 1999;25:332-5.

12. Heling I, Chandler NP. Antimicrobial effect of irrigant combinations within dentinal tubules. Int Endod J. 1998;31:8-14.

13. Delany GM, Patterson SS, Miller CH, Newton CW. The effect of chlorhexidine gluconate irrigation on the root canal flora of freshly extracted necrotic teeth. Oral Surg Oral Med Oral Pathol. 1982;53:51823.

14. Lynne RE, Liewehr FR, West LA, Patton WR, Buxton TB, McPherson JC. In vitro antimicrobial activity of various medication preparations on E.Faecalis in root canal dentin. J Endod. 2003;29:187-90.

15. Jeansonne MJ, White RR. A comparison of $2.0 \%$ chlorhexidine gluconate and $5.25 \%$ sodium hypochlorite as antimicrobial endodontic irrigants. J Endod. 1994;20:276-8.

16. Shabahang S, Torabinejad M. Effect of MTAD on Enterococcus feacalic-contaminated root canals of extracted teeth. J Endod. 2003;29:576-9.

17. Menezes MM, Valera MC, Jorge AO, Koga-Ito CY, Camargo CH, Mancini MN. In vitro evaluation of the effectiveness of irrigants and intracanal medicaments on microorganisms within root canals. Int Endod J. 2004:37:311-9.

18. Estrela C, Silva JA, de Alencar AH, Leles CR, Decurcio DA. Efficacy of sodium hypochlorite and chlorhexidine against Enterococcus faecalis-a systematic review. J Appl Oral Sci. 2008; 16:364-8. 